RU Освоение реферативных средств на занятиях по русскому языку как иностранному (научный стиль речи):
на примере обучения написанию аннотации

Сицына-Кудрявцева А. Н.

Аннотация. Цель работы - установить связь между уровнем сформированности навыка владения иностранными учащимися реферативными средствами русского языка и их способностью создавать грамотные письменные научные тексты. В исследовании рассматриваются обучающие приемы, применяемые на занятиях по русскому языку как иностранному (научный стиль речи), которые позволяют выработать у учащихся умение создавать вторичные научные тексты. Научная новизна исследования состоит в том, что предложен алгоритм, следуя которому, возможно развить у иностранных учащихся умение грамотно строить письменные научные тексты. В результате исследования сформулированы основные методические принципы, руководствуясь которыми, у иностранных учащихся возможно успешно сформировать навыки правильного написания научных текстов.

\title{
Mastering Abstracting Means in Russian as a Foreign Language Classes (Scientific Style of Speech): By the Example of Teaching How to Write an Abstract
}

\author{
Sitsyna-Kudryavtseva A. N.
}

\begin{abstract}
The work aims to reveal relationship between foreign students' level of proficiency in abstracting means of the Russian language and their ability to create well-written scientific texts. The study examines the teaching techniques used in Russian as a foreign language classes (scientific style of speech) which allow students to acquire the skill of creating secondary scientific texts. The paper is novel in that the researcher has proposed an algorithm which makes it possible for foreign students to develop the ability to compose well-penned scientific texts. As a result of the study, the researcher has formulated the main methodological principles guided by which it is possible for foreign students to successfully master the skills of creating well-written scientific texts.
\end{abstract}

\section{Введение}

При обучении иностранных учащихся вузов на занятиях по русскому языку как иностранному научному стилю речи важнейшим компонентом такого обучения является развитие навыков грамотного создания письменных научных текстов, а именно: аннотации, реферата, первичных и вторичных тезисов, научной статьи. Высокий уровень сформированности таких навыков позволит учащимся в дальнейшем успешно реализовать свою профессиональную компетенцию и проявить себя в учебно-научной и научной сферах деятельности.

На первичном этапе освоения научного стиля речи иностранные учащиеся должны познакомиться с реферативными средствами языка, под которыми понимаются частотные глагольно-именные сочетания и речевые средства, отвечающие за логику развития научного текста, выступающие в качестве опорных единиц, за счет расширения которых специфическими лексическими средствами, характерными для той или иной области науки, происходит построение научного текста.

Теоретической базой исследования послужили труды И. Б. Авдеевой [1], Л. Е. Алексеевой [2], Т. Е. Аросевой, Л. Г. Роговой, Н. Ф. Сафьяновой [3], С. А. Вишняковой [4], Л. П. Клобуковой [5], В. Г. Костомарова, О. Д. Митрофановой [6; 7], В. Б. Куриленко [8], О. Д. Митрофановой [9; 10], в которых описываются основные методические принципы работы над освоением иностранными учащимися научного стиля речи, а также специфика создания вторичных и первичных письменных научных текстов. 
Актуальность темы исследования состоит в том, что в современной методике преподавания научного стиля речи иностранным учащимся назрела необходимость установить взаимосвязь между уровнем сформированности навыка владения реферативными средствами русского языка у обучающихся и их способностью создавать грамотные письменные научные тексты разных жанров. Кроме того, актуальность исследования обусловливается необходимостью выявить механизмы, позволяющие развить навык грамотного написания иностранными учащимися письменных научных текстов, что послужит основой для создания поэтапного алгоритма работы по обучению на занятиях по русскому языку как иностранному (научный стиль речи) построению письменных научных текстов.

Сформулируем задачи работы: 1) определить роль реферативных средств при обучении иностранных учащихся написанию научных текстов на занятиях по русскому языку как иностранному; 2) выявить взаимосвязь между уровнем сформированности навыка владения реферативными средствами и уровнем грамотности написания научных текстов (на примере написания аннотации).

В ходе исследования были применены методы лингвистического анализа и экстраполяции, позволяющие определить причинно-следственные связи между уровнем сформированности навыка владения иностранными учащимися реферативными средствами русского языка и их способностью создавать грамотные письменные научные тексты.

Практическая значимость работы заключается в том, что материалы исследования могут быть использованы в вузах, имеющих гуманитарное, естественнонаучное и техническое направления, на занятиях в группах иностранных учащихся, осваивающих дисциплины «Русский язык как иностранный (научный стиль речи)», «Академическое письмо на русском языке», а также при создании учебных пособий по русскому языку как иностранному (научный стиль речи), пособий по языку специальности.

\section{Роль реферативных средств при обучении иностранных учащихся написанию научных текстов}

Основными принципами обучения иностранных учащихся написанию научных текстов выступают принцип использования специфических «коммуникативных кодов» (теория О. Д. Митрофановой [6]) и принцип моделирования (теория С. А. Вишняковой [4]). В их основе лежит идея о том, что любой научный текст строится в соответствии с заданными заранее структурами, наполняющимися одними и теми же речевыми сочетаниями, выбираемыми из перечня возможных вариантов. К примеру, при создании фрагментов научных текстов, содержащих описание структуры научного объекта, обычно используют какие-либо из следующих грамматических моделей: что обладает чем, что имеет какой цвет / какую форму, чему присуще что, для чего характерно что, что способно что делать, что способно к чему, что какой формы / какого цвета / какого строения, что с каким свойством, что состоит из чего, что содержит что, что делится на что чем, что равно чему, что включает в себя что, что достигает чего (что достигается чем / за счёт чего), что составляет что, что входит в состав чего, что является составной частью чего.

Известно, что структурно-языковые модели письменных научных текстов остаются практически неизменными на протяжении многих десятилетий. Изменения в научном стиле речи происходят прежде всего за счет расширения терминосистем. Таким образом, при обучении иностранных учащихся созданию письменных научных текстов целесообразно на подготовительном этапе сформировать для них базу реферативных средств, состоящих в первую очередь из глагольно-именных сочетаний и лексических средств, указывающих на логику развития научного текста. Одним из возможных вариантов такой базы может быть следующий (Таблица 1).

Таблица 1. Реферативные средства языка

\begin{tabular}{|c|c|c|c|}
\hline \multicolumn{2}{|c|}{ Частотные глагольно-именные сочетания } & \multicolumn{2}{|c|}{$\begin{array}{c}\text { Лексические средства, указывающие } \\
\text { на логику развития научного текста }\end{array}$} \\
\hline Группа по значению & Глагольно-именные сочетания & Группа по значению & Лексические средства \\
\hline $\begin{array}{l}\text { Описание научного } \\
\text { объекта }\end{array}$ & $\begin{array}{l}\text { Описывать/описать процесс, спо- } \\
\text { соб, вид; определять/определить } \\
\text { понятие, условие, преимущества, } \\
\text { недостатки; характеризовать/ } \\
\text { охарактеризовать процесс, свой- } \\
\text { ство, отношение; называть/на- } \\
\text { звать признаки, свойства, особен- } \\
\text { ности; формулировать/сформули- } \\
\text { ровать вопрос, проблему, задачу; } \\
\text { перечислять достоинства, недо- } \\
\text { статки, преимущества }\end{array}$ & $\begin{array}{l}\text { Порядок изложения } \\
\text { информации }\end{array}$ & $\begin{array}{l}\text { Сначала, вначале, затем, } \\
\text { прежде всего, в первую оче- } \\
\text { редь, наконец, во-первых, } \\
\text { во-вторых, перейдем к сле- } \\
\text { дующей части }\end{array}$ \\
\hline $\begin{array}{l}\text { Изложение истории } \\
\text { вопроса, имеющихся } \\
\text { научных данных }\end{array}$ & $\begin{array}{l}\text { Рассказывать/рассказать о фак- } \\
\text { тах, событиях, истории; изла- } \\
\text { гать/изложить факты, события, } \\
\text { историю; сообщать/сообщить } \\
\text { информацию, данные, факты; ин- } \\
\text { формировать о фактах, результа- } \\
\text { тах, событиях; показывать/пока- } \\
\text { зать ход исследования/эксперимен- } \\
\text { та, историю вопроса/развития }\end{array}$ & $\begin{array}{l}\text { Введение основной } \\
\text { информации }\end{array}$ & $\begin{array}{l}\text { Основное внимание уделя- } \\
\text { ется..., остановимся на..., } \\
\text { далее, в основной части } \\
\text { работы... }\end{array}$ \\
\hline
\end{tabular}




\begin{tabular}{|c|c|c|c|}
\hline \multicolumn{2}{|c|}{ Частотные глагольно-именные сочетания } & \multicolumn{2}{|c|}{$\begin{array}{l}\text { Лексические средства, указывающие } \\
\text { на логику развития научного текста }\end{array}$} \\
\hline Группа по значению & Глагольно-именные сочетания & Группа по значению & Лексические средства \\
\hline \multirow[t]{7}{*}{$\begin{array}{l}\text { Установление связи, } \\
\text { взаимосвязи между } \\
\text { объектами, выстраивание } \\
\text { логических цепочек }\end{array}$} & \multirow{7}{*}{$\begin{array}{l}\text { Анализировать причины, данные, } \\
\text { события, результаты; доказывать/ } \\
\text { доказать тезис, гипотезу, предпо- } \\
\text { ложение, теорему, утверждение, } \\
\text { правильность, ложность; утвер- } \\
\text { жать положение; обосновывать/ } \\
\text { обосновать метод, правильность, } \\
\text { ложность; исследовать проблему, } \\
\text { причины, взаимосвязь; объяснять/ } \\
\text { объяснить причины, связь, взаимо- } \\
\text { связь, правильность, ложность; } \\
\text { выявлять/выявить закономерность, } \\
\text { связь, взаимосвязь, ошибки; рас- } \\
\text { сматривать/рассмотреть связь, } \\
\text { взаимосвязь, логику, отношение; } \\
\text { раскрывать/раскрыть причины, } \\
\text { недостатки; устанавливать/уста- } \\
\text { новить причины, закономерности, } \\
\text { связь, взаимосвязь, логику сравни- } \\
\text { вать/сравнить обвекты, явления, } \\
\text { данные, причины; сопоставлять/со- } \\
\text { поставить объекты, мнения, точ- } \\
\text { ки зрения, факты; противопостав- } \\
\text { лять/противопоставить обвекты, } \\
\text { теории, данные, факты, мнения }\end{array}$} & $\begin{array}{l}\text { Введение } \\
\text { дополнительной } \\
\text { информации }\end{array}$ & $\begin{array}{l}\text { При этом, кроме того, } \\
\text { следует заметить, вместе } \\
\text { с тем, в то же время, более } \\
\text { того, здесь же, а также, } \\
\text { нарядус... }\end{array}$ \\
\hline & & $\begin{array}{l}\text { Введение } \\
\text { иллюстративного } \\
\text { материала }\end{array}$ & $\begin{array}{l}\text { Например, так, на кон- } \\
\text { кретном примере, с исполь- } \\
\text { зованием графической схе- } \\
\text { мы, продемонстрируем }\end{array}$ \\
\hline & & $\begin{array}{l}\text { Выражение согласия } \\
\text { или несогласия }\end{array}$ & $\begin{array}{l}\text { Разумеется, конечно, безус- } \\
\text { ловно, бесспорно, в самом } \\
\text { деле, очевидно, действи- } \\
\text { тельно, видимо, понятно, } \\
\text { сомнительно, не вызывает } \\
\text { сомнений/возражений, } \\
\text { нельзя не согласиться с... }\end{array}$ \\
\hline & & $\begin{array}{l}\text { Выражение собственной } \\
\text { точки зрения }\end{array}$ & $\begin{array}{l}\text { Представляется, думается, } \\
\text { на наш взгляд, по нашему } \\
\text { мнению }\end{array}$ \\
\hline & & $\begin{array}{l}\text { Ссылка на источник } \\
\text { информации }\end{array}$ & $\begin{array}{l}\text { Как известно, по словам..., } \\
\text { как сказано в..,, общеиз- } \\
\text { вестно, по мнению..., как } \\
\text { писал..., исходя..., считается }\end{array}$ \\
\hline & & $\begin{array}{l}\text { Сопоставление } \\
\text { и противопоставление } \\
\text { объектов }\end{array}$ & $\begin{array}{l}\text { Но, а, не только..., } \\
\text { но и..., наоборот, напро- } \\
\text { тив, зато, с одной сторо- } \\
\text { ны, с другой стороны, не- } \\
\text { смотря на..., в противопо- } \\
\text { ложность (чему?) }\end{array}$ \\
\hline & & Формулирование вывода & $\begin{array}{l}\text { Следовательно, в заключе- } \\
\text { ние можно сказать, таким } \\
\text { образом, итак, приходим } \\
\text { квыводу }\end{array}$ \\
\hline
\end{tabular}

После ознакомления иностранных учащихся с приведенной базой реферативных средств следует перейти к формированию у них умения ею грамотно пользоваться. Хорошо сформированное умение владеть реферативными глагольно-именными сочетаниями и лексическими средствами, указывающими на логику развития научного текста, даст возможность иностранным учащимся успешно создавать прежде всего вторичные письменные научные тексты, а именно: аннотацию, вторичные тезисы, различные виды рефератов, поскольку приведенные выше лексемы и сочетания помогут учащимся правильно выявить функцию предиката первичного текста, а знание их значения - грамотно выстроить логику создаваемого научного текста. Таким образом, их уместное применение будет способствовать, с одной стороны, правильной передаче главного содержания первичного текста, с другой стороны, созданию необходимой структурной модели текста.

Для того чтобы сформировать навык грамотного использования реферативных средств, на начальном этапе следует научить иностранных учащихся составлению на их основе мини-текстов, отвечающих тем или иным задачам (описать научный объект, дать его характеристику, определить место объекта в ряду других, указать качественный и количественный состав и т.п.). При этом следует акцентировать внимание иностранных учащихся на том, какие группы реферативных средств следует использовать, чтобы создать тот или иной тип текста. Например, для того чтобы создать описание научного объекта, прежде всего используют глагольно-именные сочетания, относящиеся к группе с аналогичным значением (подробнее см. Таблицу 1), а также лексические средства, указывающие на логику развития научного текста, групп со значением «Порядок изложения информации», «Введение иллюстративного материала».

Задания, целью которых является развитие навыка грамотного использования реферативных средств при построении мини-текстов, могут быть следующими: 1) прочитайте небольшой научный текст, содержащий описание научного объекта (информацию о связи/взаимосвязи научных объектов и т.п.). Используя уместные реферативные средства языка, изложите коротко его основное содержание (5-6 предложений); 2) опираясь на предложенный рисунок/схему (дается рисунок с изображением научного объекта, рисунок, показывающий связь/взаимосвязь между научными объектами, схема какого-либо научного процесса и т.п.), составьте небольшой текст-описание/текст-характеристику (5-6 предложений). При написании текста используйте уместные реферативные средства.

После того как иностранные обучающиеся достигают достаточного уровня сформированности навыка правильного использования реферативных средств и могут, применяя их, грамотно с точки зрения структуры и языка составлять небольшие вторичные научные тексты, можно переходить к обучению создавать вторичные тексты определенных жанров. Такое обучение следует начать с вторичных научных текстов, 
отличающихся небольшим объемом и несложной композиционной структурой, а затем переходить к более сложным. При этом основным принципом, руководствуясь которым у иностранных учащихся возможно успешно сформировать навыки правильного написания научного текста, будет являться принцип его моделирования с использованием тех или иных известных реферативных средств, выбор которых будет определять тип текста (описание научного объекта, его характеристика, определение места объекта в ряду других и т.п.).

Одним из несложных по композиции и языковому оформлению вторичных научных текстов является аннотация. Именно с нее и следует начать обучение иностранных учащихся составлению вторичных научных текстов.

\section{Навык владения реферативными средствами как показатель способности грамотного написания вторичных научных текстов иностранными учащимися (на примере написания аннотации)}

Аннотация, как и любой научный текст, имеет четкую композиционную структуру, каждый компонент которой должен быть наполнен определенным содержанием. Строго определенные содержательные рамки композиционных элементов аннотации дают возможность создать перечни вариативных реферативных языковых средств, умело используя которые, можно создать качественный научный текст данного жанра. Иностранные учащиеся, хорошо владеющие реферативными средствами языка, зная модель аннотации и ориентируясь в смысловой части каждого ее композиционного компонента, могут успешно создавать научные тексты этого жанра. Для того чтобы выработать у иностранных учащихся навык создания аннотаций, целесообразно на первичном этапе предложить им использовать структурную схему этого жанра в соотнесении ее структурных компонентов с реферативными средствами языка. Необходимо обратить внимание учащихся на то, что в зависимости от типа первичного текста, по которому создается аннотация, будет меняться набор возможных глагольно-именных сочетаний. Приведем пример композиционно-языковой структурной схемы аннотации, предлагаемой иностранным учащимся (Таблица 2).

Таблица 2. Реферативные средства языка, используемые для написания аннотации

\begin{tabular}{|c|c|c|}
\hline \multirow[b]{2}{*}{$\begin{array}{l}\text { Структурный } \\
\text { компонент } \\
\text { аннотации }\end{array}$} & \multicolumn{2}{|c|}{ Реферативные средства языка } \\
\hline & $\begin{array}{c}\text { Частотные } \\
\text { глагольно-именные сочетания }\end{array}$ & $\begin{array}{c}\text { Лексические средства, } \\
\text { указывающие на логику } \\
\text { развития научного текста }\end{array}$ \\
\hline \multirow{6}{*}{$\begin{array}{l}\text { Формулировка } \\
\text { проблемы, } \\
\text { цели исследования }\end{array}$} & Описание научного объекта & Порядок изложения информации \\
\hline & Описывать/описать процесс, способ, вид & \multirow[t]{5}{*}{ В первую очередь, прежде всего } \\
\hline & Изложение истории вопроса, имеющихся научных данных & \\
\hline & $\begin{array}{l}\text { Излагать/изложить факты, события, историю; показывать/ } \\
\text { показать ход исследования/эксперимента, историю вопроса/ } \\
\text { развития }\end{array}$ & \\
\hline & $\begin{array}{l}\text { Установление связи, взаимосвязи между объектами, выстраи- } \\
\text { вание логических цепочек }\end{array}$ & \\
\hline & $\begin{array}{l}\text { Анализировать причины, данные, события, результаты; } \\
\text { исследовать проблему, причины, взаимосвязь; рассматри- } \\
\text { вать/рассмотретьсвязь, взаимосвязь, логику, отношение }\end{array}$ & \\
\hline \multirow{4}{*}{$\begin{array}{l}\text { Демонстрация } \\
\text { новизны } \\
\text { исследования }\end{array}$} & Описание научного объекта & $\begin{array}{l}\text { Введение иллюстративного } \\
\text { материала }\end{array}$ \\
\hline & $\begin{array}{l}\text { Характеризовать/охарактеризовать процесс, свойство, от- } \\
\text { ношение; называть/назвать признаки, свойства, особенности }\end{array}$ & \multirow{3}{*}{$\begin{array}{l}\text { На конкретном примере, } \\
\text { с использованием графической } \\
\text { схемы }\end{array}$} \\
\hline & $\begin{array}{l}\text { Установление связи, взаимосвязи между объектами, выстраи- } \\
\text { вание логических цепочек }\end{array}$ & \\
\hline & $\begin{array}{l}\text { Доказывать/доказать тезис, гипотезу, предположение, теорему, } \\
\text { утверждение, правильность, ложность; утверждать положение; } \\
\text { обосновывать/обосновать метод, правильность, ложность; ис- } \\
\text { следовать проблему, причины, взаимосвязь; объяснять/объяснить } \\
\text { причины, связь, взаимосвязь, правильность, ложность }\end{array}$ & \\
\hline \multirow{4}{*}{$\begin{array}{l}\text { Демонстрация } \\
\text { результатов } \\
\text { исследования }\end{array}$} & Описание научного объекта & \multirow[t]{4}{*}{-} \\
\hline & $\begin{array}{l}\text { Определять/определить понятие, условие, преимущества, } \\
\text { недостатки }\end{array}$ & \\
\hline & $\begin{array}{l}\text { Установление связи, взаимосвязи между объектами, вы- } \\
\text { страивание логических цепочек }\end{array}$ & \\
\hline & $\begin{array}{l}\text { Раскрывать/раскрыть причины, недостатки; устанавли- } \\
\text { вать/установить причины, закономерности, связь, взаимо- } \\
\text { связь, логику; выявлять/выявить закономерность, связь, взаи- } \\
\text { мосвязь, ошибки }\end{array}$ & \\
\hline
\end{tabular}

Усвоив структуру аннотации и реферативные средства, необходимые для написания той или иной ее части (подробнее см. Таблицу 2), иностранные учащиеся могут приступать к выполнению тренировочных заданий 
по составлению текстов этого жанра. При этом целесообразно предлагать им разные типы первичных научных текстов, как то: содержащих описания научных объектов, их связи и взаимосвязи, историю развития различных научных теорий и т.п. Это поможет выработать у иностранных учащихся умение безошибочно выбирать для написания аннотации наиболее уместные реферативные средства из возможных предлагаемых вариантов. Тренировочные задания для выработки навыка написания аннотаций могут быть следующих типов: 1) изучите предложения первичного научного текста, содержащие информацию о проблеме, цели исследования, его новизне, результатам, полученным в ходе исследования. Используя данную информацию, напишите аннотацию. При работе над составлением текста аннотации выбирайте наиболее подходящие по смыслу реферативные средства; 2) прочитайте первичный научный текст, найдите в нем информацию о проблеме, цели исследования, его новизне, результатам, полученным в ходе исследования. Используя наиболее подходящие по смыслу реферативные средства, напишите аннотацию предложенного научного текста.

Таким образом, обучение иностранных учащихся написанию аннотации должно идти по следующему пути: 1) изучение и освоение композиционных элементов аннотации в связке с реферативными глагольноименными сочетаниями и лексическими средствами, отвечающими за логику построения научного текста; 2) выработка навыка написания аннотаций по заданным параметрам (учащимся дается коротко сформулированная проблема, цель исследования, его новизна и результаты); 3) формирование у учащихся умения создавать аннотации по первичным научным текстам. При этом чем лучше у иностранных учащихся сформирован навык владения реферативными средствами языка, тем быстрее и качественнее протекает процесс их обучения написанию аннотации.

Основными принципами при обучении иностранных учащихся написанию аннотации выступают уже упомянутый нами принцип моделирования научных текстов тех или иных типов и жанров и принцип коммуникативной направленности, под которым в нашем случае понимается формирование у обучающихся нужных языковых умений и навыков с применением метода экстраполяции, то есть прогнозирования и выбора необходимых языковых средств из нескольких тематических групп.

\section{Заключение}

Из вышеизложенного в рамках исследования можно сделать следующие выводы.

1. Представление реферативных средств на занятиях по русскому языку как иностранному (научный стиль речи) в виде тематических групп и дальнейшая выработка навыка грамотного и уместного их использования позволяют подготовить иностранных учащихся к успешному освоению ими различных жанров вторичных научных текстов.

2. Чем лучше развит навык владения реферативными средствами русского языка у иностранных обучающихся, тем легче и быстрее они способны научиться создавать вторичные научные тексты.

3. Алгоритм работы с иностранными учащимися по выработке у них умения создавать вторичные письменные научные тексты можно представить в следующем виде: 1) освоение реферативных средств русского языка; 2) выработка умения писать научные мини-тексты с использованием реферативных средств; 3) освоение композиционных структур вторичных письменных научных текстов в связке с характерными для каждого элемента структуры реферативными средствами; 4) формирование навыка написания того или иного жанра вторичного научного текста с опорой на известную композицию и уместные для каждого конкретного случая реферативные средства.

4. Основными методическими принципами, руководствуясь которыми, возможно успешно сформировать у иностранных учащихся навык грамотного написания научных текстов, выступают принцип моделирования научного текста и принцип коммуникативной направленности.

Перспективы дальнейшего исследования мы видим в разработке общего алгоритма обучения на занятиях по русскому языку как иностранному (научный стиль речи) учащихся написанию вторичных и первичных научных текстов с опорой на реферативные средства языка, руководствуясь которым, возможно будет постепенно развивать навык создания письменных научных текстов разных жанров.

\section{Источники | References}

1. Авдеева И. Б. Корни новой парадигмы при изучении аутентичной инженерной коммуникации // Сборник научных трудов, посвященный юбилею члена-корреспондента Российской академии словесности, доктора филологических наук, профессора О. Д. Митрофановой: в 2-х т. Тула: Изд-во ТулГУ, 2010. Т. 1. С. 3-8.

2. Алексеева Л. Е. Методика обучения профессионально ориентированному иностранному языку: курс лекций: метод. пособие. СПб.: Филол. фак. СПбГУ, 2007. 136 с.

3. Аросева Т. Е., Рогова Л. Г., Сафьянова Н. Ф. Научный стиль речи. Технический профиль. М.: Русский язык. Курсы, 2017. 312 с.

4. Вишнякова С. А. Современные концепции исследования обучения пониманию научного текста на основе моделирования // Сборник научных трудов, посвященный юбилею члена-корреспондента Российской академии словесности, доктора филологических наук, профессора О. Д. Митрофановой: в 2-х т. Тула: Изд-во ТулГУ, 2010. Т. 1. С. 74-81. 
5. Клобукова Л. П. Обучение языку специальности. М.: Изд-во МГУ, 1987. 81 с.

6. Костомаров В. Г., Митрофанова О. Д. Методика преподавания русского языка как иностранного. М.: Русский язык, 1990. 270 с.

7. Костомаров В. Г., Митрофанова О. Д. Методическое руководство для преподавателей русского языка иностранцам. Изд-е 4-е, испр. М.: Рус. яз., 1988. 155 с.

8. Куриленко В. Б. Систематизация языкового материала в Программе по РКИ для студентов нефилологических специальностей: II сертификационный уровень, профессиональные модули // Сборник научных трудов, посвященный юбилею члена-корреспондента Российской академии словесности, доктора филологических наук, профессора О. Д. Митрофановой: в 2-х т. Тула: Изд-во ТулГУ, 2010. Т. 1. С. 172-181.

9. Митрофанова О. Д. Научный стиль речи: проблемы обучения. Изд-е 2-е, перераб. и доп. М.: Рус. яз., 1985.130 с.

10. Митрофанова О. Д. Язык научно-технической литературы. М.: Изд-во МГУ, 1973. 144 с.

\section{Информация об авторах | Author information}

RU Сицына-Кудрявцева Алевтина Николаевна ${ }^{1}$, к. филол. н.

${ }^{1}$ Национальный исследовательский ядерный университет «МИФИ», г. Москва

EN Sitsyna-Kudryavtseva Alevtina Nikolaevna ${ }^{1}, \mathrm{PhD}$

${ }^{1}$ National Research Nuclear University MEPhI (Moscow Engineering Physics Institute), Moscow

${ }^{1}$ ansitsyna@mephi.ru

\section{Информация о статье | About this article}

Дата поступления рукописи (received): 11.04.2021; опубликовано (published): 30.06.2021.

Ключевые слова (keywords): реферативная форма; реферативные средства русского языка; научный текст; научные жанры; письменный текст; abstract form; abstracting means of the Russian language; scientific text; scientific genres; written text. 